\title{
Thorotrast associated nodular regenerative hyperplasia of the liver
}

\author{
T W Beer, N J Carr, P J Buxton
}

\section{Department of \\ Histopathology, The \\ Royal Hospital Haslar, \\ Gosport, Hampshire \\ PO12 2AA, UK \\ $\mathrm{T}$ W Beer \\ N J Carr}

Department of

Radiology, The Royal

Hospital Haslar

P J Buxton

Correspondence to:

Dr Beer.

Accepted for publication 25 August 1998

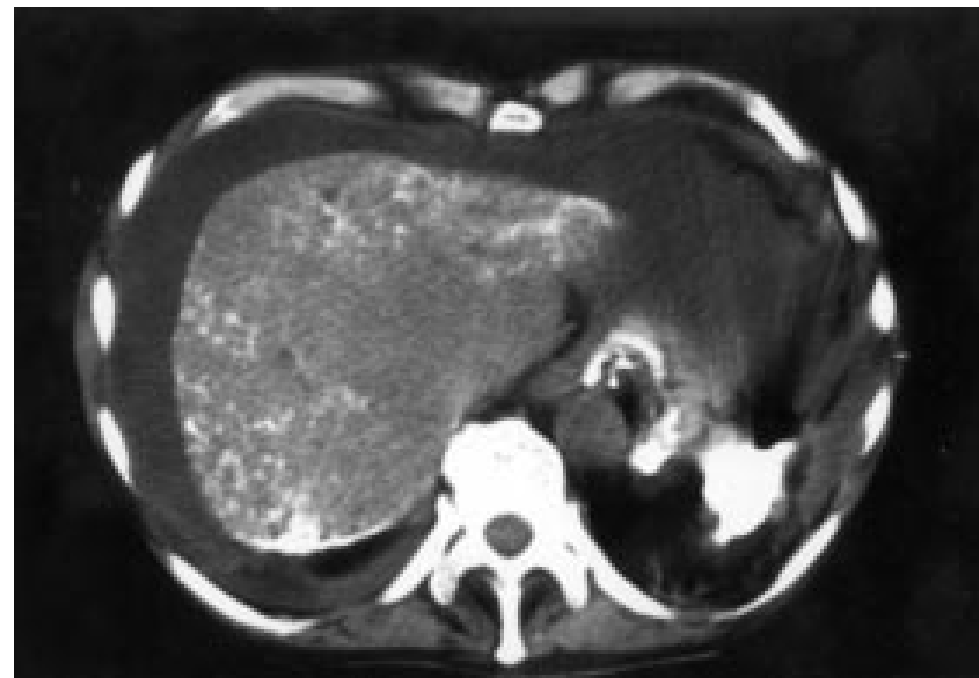

Figure 1 Axial computed tomography of the upper abdomen with intravenous contrast medium, showing gross ascites with high density material in a reticulate pattern throughout the liver, consistent with Thorotrast. The spleen is shrunken and also of high density.

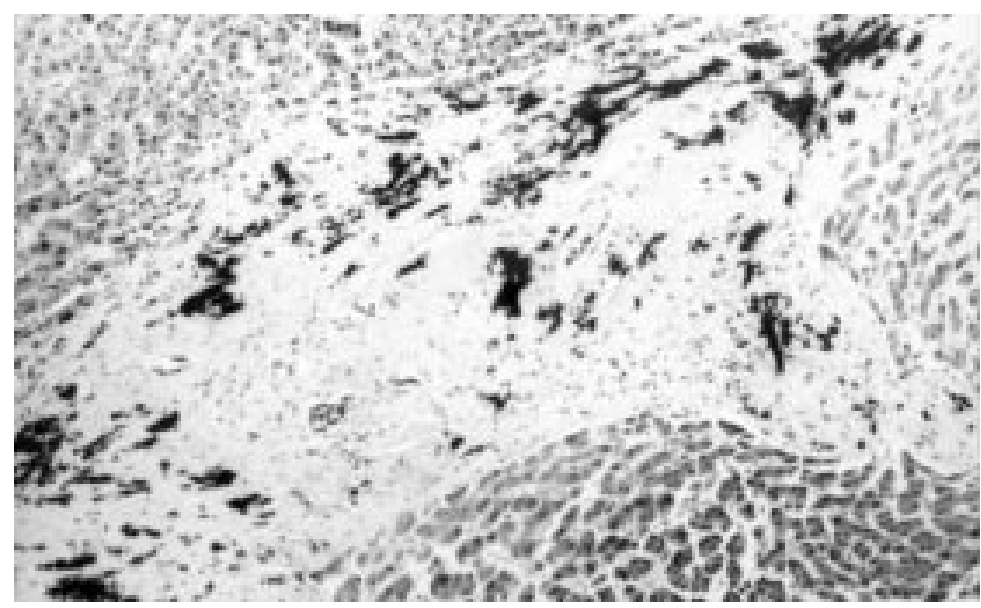

Figure 2 Granules of Thorotrast pigment in a portal tract (haematoxylin and eosin).
An ultrasound scan suggested hepatic cirrhosis but computed tomography, using intravenous contrast, revealed high density material in a reticular pattern throughout the liver (fig 1). The spleen was also of high density. Liver function tests were deranged, with a raised $\gamma$-glutamyltransferase (1184 IU/litre, normal range 8-78) and alkaline phosphatase (393 IU/litre, normal range 38-126), but normal bilirubin (12.5 $\mu \mathrm{mol} /$ litre, normal range 3-22). The patient died before a definitive diagnosis could be made.

Three years previously he had a Duke's stage $C$ colonic adenocarcinoma resected and had been well in the interim, taking no drugs. Forty five years before, in 1951, he had a spontaneous subarachnoid haemorrhage owing to rupture of an aneurysm on the right cerebral artery identified on cerebral angiography.

At necropsy there was extensive ascites and the liver was nodular throughout, weighing $1580 \mathrm{~g}$. A tumour nodule $40 \mathrm{~mm}$ diameter was present at the anterior surface of the right lobe of the liver and there was generalised peritoneal thickening. Ischaemic heart disease caused by coronary artery atheroma was present, and there were also multiple small pulmonary thromboemboli. No splenic enlargement or varices were seen to suggest portal hypertension.

Liver histology showed nodular regenerative hyperplasia characterised by diffusely distributed nodules of regenerating hepatocytes throughout the liver, with compression of reticulin around the nodules but without associated fibrous tissue. There was also conspicuous brown pigment in portal tracts (fig 2). Microanalysis of the pigment by $x$ ray showed it to be thorium-rich (fig 3), consistent with Thorotrast. ${ }^{1}$ Although the majority of portal tracts contained normal portal vein branches, there appeared to be loss of the veins in some. The hepatic arteries and veins were otherwise normal. There was carcinomatosis peritonei and the liver tumour was an area of metastatic colonic adenocarcinoma.

\section{Discussion}

Nodular regenerative hyperplasia of the liver has been recognised since at least the early 1950 s under a variety of synonyms, occurring in up to $0.6 \%$ of necropsies. ${ }^{2}$ Many clinicopathological processes predispose to its development but the most frequent associations are with immune complex, lymphoproliferative, and myeloproliferative diseases. ${ }^{34}$ A spectrum of drugs and toxins has also been implicated, most notably steroids and cytotoxic agents. Hepatic irradiation has been associated with 


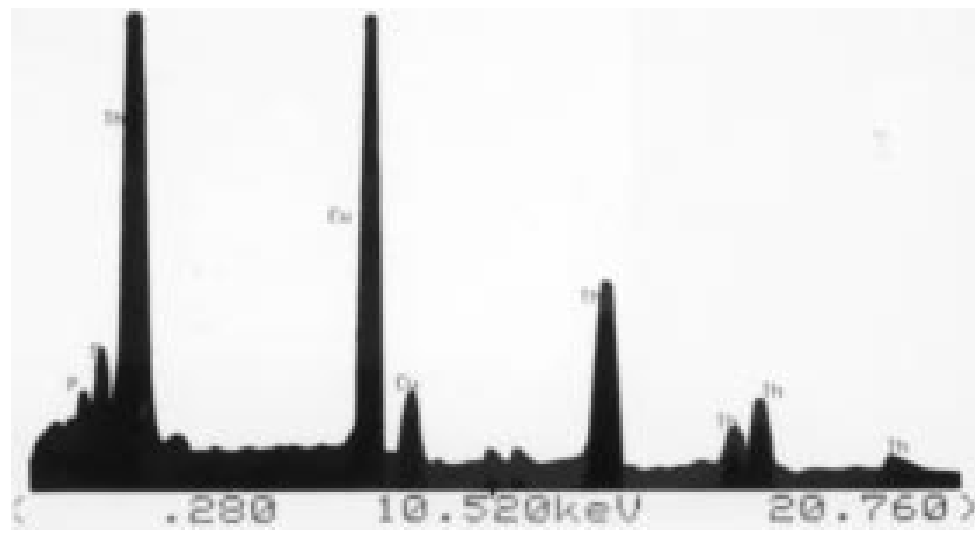

Figure $3 x$ Ray microanalysis of the liver pigment showing multiple peaks corresponding to isotopes of thorium (Th). Copper peaks (Cu) are from the specimen support grid.

nodular regenerative hyperplasia in a patient with Hodgkin's disease.

Thorotrast was widely used between 1928 and 1955 as an $x$ ray contrast medium. It contains thorium dioxide with a radioactive half life of approximately 400 years. After intravenous injection it is deposited in the reticuloendothelial system, the majority being stored in the liver. Virtually none is eliminated. Various liver neoplasms have been reported after Thorotrast administration, most notably angiosarcoma and cholangiocarcinoma. There is also an increased incidence of hepatocellular carcinoma and possibly an increased risk of cancers in non-hepatic sites. ${ }^{5}$ Cirrhosis of the liver has been reported, and a 20 -fold increase in risk calculated. ${ }^{6}$ Further non-neoplastic liver changes described include veno-occlusive disease, ${ }^{7}$ hepatoportal sclerosis, focal nodular hyperplasia, ${ }^{8}$ and ill defined liver nodularity. ${ }^{9}$

There are two previous reviews alluding to the role of Thorotrast in the development of nodular regenerative hyperplasia, ${ }^{210}$ but this case is the first in which the pathological findings are fully documented.
Nodular regenerative hyperplasia is thought to be a regenerative phenomenon following ischaemia of the hepatic acinus which may follow damage to small hepatic arteries or portal veins. ${ }^{2}$ There is evidence that Thorotrast may produce vascular damage which in some cases has led to infarction from vessel occlusion. ${ }^{11}$ Damage to carotid arteries has been fatal in some cases. ${ }^{12}$ In our case, nodular regenerative hyperplasia was associated with a reduction in portal vein branches, possibly caused by chronic alpha irradiation from Thorotrast.

We are grateful to Professor R N M MacSween for his comments on this case, to $\mathrm{Mr} \mathrm{P}$ Runchman for permission to report the case, and to the Electron Microscopy Unit at Southampton General Hospital for $x$ ray microanalysis.

1 Bowen JH, Woodward BH, Mossler JA, et al. Energy dispersive $x$-ray detection of thorium dioxide. Arch Pathol Lab Med 1980;104:459-61.

2 Dachman AH, Ros PR, Goodman ZD, et al. Nodular regenerative hyperplasia of the liver: clinical and radiologic observations. Am f Roentgenol 1987;148:717-22.

3 Wanless IR. Micronodular transformation (nodular regenerative hyperplasia) of the liver: a report of 64 cases among 2500 autopsies and a new classification of benign hepatocellular nodules. Hepatology 1990;11:787-97.

4 Stomeyer FW, Ishak KG. Nodular transformation (nodular "regenerative" hyperplasia) of the liver. Hum Pathol "regenerative"

5 Andersson M, Vyberg M, Visfeldt J, et al. Primary liver tumours among Danish patients exposed to Thorotrast. Radiat Res 1994;137:262-73

6 Kato I, Kido C. Increased risk of death in Thorotrastexposed patients during the late follow-up period. $\mathcal{F} p n$ f Cancer Res 1987;78:1187-92.

7 Dejgaard A, Krogsgaard K, Jacobsen M. Veno-occlusive disease and peliosis of the liver after Thorotrast administration. Virchows Arch A Pathol Anat Histopathol 1984;403:8794.

8 Sano Y, Nakamura S, Kitazawa T, et al. Focal nodular hyperplasia-like lesion of the liver associated with Thorotrast liver disease-report of a case. Gan To Kagaku Ryoho 1985;31:1445-50.

9 Velasquez G, Ward CF, Bohrer SP. Thorium dioxide: still around. South Med $\mathcal{F} 1985 ; 78: 743-5$.

10 Popper H, Thomas LB, Schaffner F, et al. Interaction between sinusoidal cells and hepatocytes in human and experimental angiosarcoma induced by environmental factors. In: Wisse E, Knook DL, eds. Kupffer cells and other liver sinusoidal cells. Amsterdam: Elsevier/North Holland Biomedical Press, 1977

1 Isner JM, Sazama KJ, Roberts WC. Vascular complications of thorium dioxide. Am F Med 1978;64:1069-74.

12 Trible WM, Small A. Thorium dioxide granuloma of the neck: a report of four cases. Laryngoscope 1976;86:1633-8. 